\title{
Video-assisted thoracic surgery segmentectomies: Brazilian experience
}

\author{
Spencer Marcantonio Camargo, Stephan Adamour Soder, Fabiola Adelia Perin, José Carlos Felicetti, José \\ de Jesus Peixoto Camargo
}

Pavilhão Pereira Filho, Irmandade Santa Casa de Misericórdia de Porto Alegre, Porto Alegre, Brazil

Contributions: (I) Conception and design: All authors; (II) Administrative support: All authors; (III) Provision of study materials or patients: All authors; (IV) Collection and assembly of data: All authors; (V) Data analysis and interpretation: All authors; (VI) Manuscript writing: All authors; (VII) Final approval of manuscript: All authors.

Correspondence to: Spencer Marcantonio Camargo. Thoracic Surgery and Lung Transplantation Unit, Pavilhão Pereira Filho, Dom Vicente Scherer Hospital, Irmandade Santa Casa de Misericórdia, Porto Alegre, Brazil. Email: smcamargo@terra.com.br.

\begin{abstract}
There is growing enthusiasm with lung resections by video-assisted thoracic surgery (VATS) technique in Brazil. The benefits of these minimally invasive procedures and their incorporation in the routine of many Brazilian centers produced a significant increase of sublobar and lobar resections in the country. The changes in our daily practice, including improvements in lung cancer staging, the rising of lung cancer screening programs and the analysis of several recent studies showing equivalent long-term outcomes with sublobar resections, while we treat often an elderly and poor performance population, have made the thoracic surgeon to look to a sublobar resection as a potentially curative procedure. We sought to analyze the Brazilian and institutional experience with VATS sublobar anatomical resections for treatment of benign and malignant diseases, and discuss technical aspects as well. Even though is much underreported, the outcomes of VATS segmentectomies resemble what is observed around the world and constitute in an effective surgery when well indicated. The Brazilian Society of Thoracic Surgery database is improving the notification by many centers and this better quality of data will provide us a deep knowledge about the results of our procedures national-wide.
\end{abstract}

Keywords: Video-assisted thoracic surgery (VATS); segmentectomies; lung cancer

Received: 31 July 2018; Accepted: 09 October 2018; Published: 15 November 2018.

doi: 10.21037 /jovs.2018.11.01

View this article at: http://dx.doi.org/10.21037/jovs.2018.11.01

\section{Introduction}

Since 1995, when the results of the Lung Cancer Study Group (LCSG) trial (1) showed better outcomes of lobectomy compared to sublobar resections to treat stage IA non-small cell lung cancer (NSCLC) and standardized the lobectomy as the choice procedure in T1N0 tumors, many changes in the lung cancer staging and treatment occurred. The development of video-assisted thoracic surgery (VATS) procedures and improvement of anesthesic and surgical techniques allowed lower post-operative morbimortality and faster recovery. The demonstration of reduced mortality in a selected population with lung cancer screening programs, a growing identification of small nodules and the aging of population have led the thoracic surgery community to renew his interests into sublobar resection.

In the last decade, a lot of controversy has permeated the discussions $(2,3)$ about the efficacy of sublobar resections to treat $\mathrm{T} 1 \mathrm{a}-\mathrm{bN} 0 \mathrm{M} 0$ tumors, based in retrospective cohorts with conflicting results. The main controversy is originate from the lack of appropriate data record about the indication of sublobar resection: if it was performed with curative intentions in a patient that could tolerate a major resection ("intentional procedure") or if it was chose in order to spare parenchyma in older or weakened patients who doesn't have adequate cardiopulmonary reserve to tolerate lobectomy ("non-intentional procedure"). These 
two divergent scenarios mixed in the retrospective studies without preoperative objectives and adequate information give unclear conclusions about their results.

Nowadays, six prospective trials with more actual and appropriate inclusion and exclusion criteria investigating the intentional indication of sublobar resections are in progress (4) (four registered from Chinese researchers, one Japanese and one multi-continental-USA, Canada and Australia), which probably will give us more reliable conclusions. As long as these results are not available, the best recent evidence originating from several retrospective series and propensity-matched analysis studies have showed same oncological benefits with sublobar resection compared to lobectomies in tumors lower than $2 \mathrm{~cm}(5-7)$.

There are two modalities of sublobar resections: the segmentectomy, in which one or more lung segments are removed with identification of segmental arterial, venous and bronchi branches and dissection of intersegmental plane. In wedge resections the lung is cross-sectioned without consideration to segmental anatomy. Although being more laborious and complex than wedge resection, the segmentectomy allow more appropriate intralobar lymphatic dissection and preserves the oncological resection principles, providing also more distance of margin between the nodule and deeper limit. These theoretical benefits are shown in some retrospective and population-based studies, with more disease-free survival favoring the segmentectomy.

In addition to malignant diseases, the segmentectomies are still used to treat benign conditions, as bronchiectasis, fungical or other infectious or inflammatory diseases. Around the world, the surgeons are gaining expertise with segmentectomies performed by VATS technique in the treatment of these pathologies and also achieving faster recovery and less complication rate.

\section{The Brazilian experience}

In Brazil, the VATS operations began in late 1990s. However, only in the last decade has there been a significant increase in number of these procedures. Despite the incorporation of minimally invasive techniques in many centers, the published data about his results were scarce until few years ago. In 2014, a national multicentric register was created by the Brazilian Society of Thoracic Surgery (BSTS) and it allowed us to analyze what was being done in the country. The first results of this multicentric database were published in 2016- the VATS Brazil study (8) - in which 649 anatomic pulmonary resections in 18 centers were analyzed. Most patients (89.8\%) had undergone surgery for neoplastic disease. Lobectomy corresponded to the great majority $(92.1 \%)$ of the procedures accomplished, and segmentectomy was performed in 35 patients (5.4\%). The median time of chest tube inserted was 3 days and length of hospital stay was 4 days. Most patients (80\%) evolved without complications.

Our institutional experience began in 2010 and the outcomes were first published in 2017, with 117 anatomic resections analyzed (9). To date, we have performed 337 anatomic lung resections by VATS technique, being 72 segmentectomies ( $21.4 \%$ of VATS anatomical resections). The most executed resections were the superior segmentectomy (26/72 cases, $36.1 \%)$, followed by left upper lobe trisegmentectomy (22.2\%), basilar (19.4\%), lingular (9.7\%) and posterior segmentectomy (6.9\%), with $5.6 \%$ of the patients underwent to multiple segmentectomies. The median ICU length of stay, chest tube duration and hospital length of stay time were respectively 1, 2 and 3 days. There were no severe complications and no mortality.

In the last year, we performed 180 lobectomies, of which $60(33 \%)$ were by VATS technique. In the same period, among 261 sublobar resections, 146 (56\%) were performed by VATS, and the segmentectomy corresponded to $17 \%$ of VATS sublobar resections. A retrospective analysis of survival among patients underwent to sublobar and lobar resection is ongoing.

Anatomical lung resections can be indicated to treat benign and inflammatory diseases as well. Unfortunately, bronchiectasis is not an uncommon condition in Brazil and affects young and middle aged people. Despite the improvement in care of these patients, the surgery is the only option for potential cure. In selected patients with localized disease, a segmentectomy can successfully remove the sick bronchi e spare normal parenchyma. There is growing evidence about the feasibility of VATS resections for bronchiectasis with promising outcomes $(10,11)$. In our casuistic, eight patients (11.1\%) were underwent to VATS segmentectomies for this disorder, with three bilateral sequential resections. Despite adhesions in pleural cavity and inflammatory process, only one patient required conversion to open surgery due to gross adhesions of lymph nodes over pulmonary artery branches. However, none patient needed blood transfusion and all patients had a postoperative course uneventful.

For segmentectomies of lower lobes, we usually utilize the two-port technique. When a segmentectomy of upper lobes is intended, we often proceeded to a third port, so 


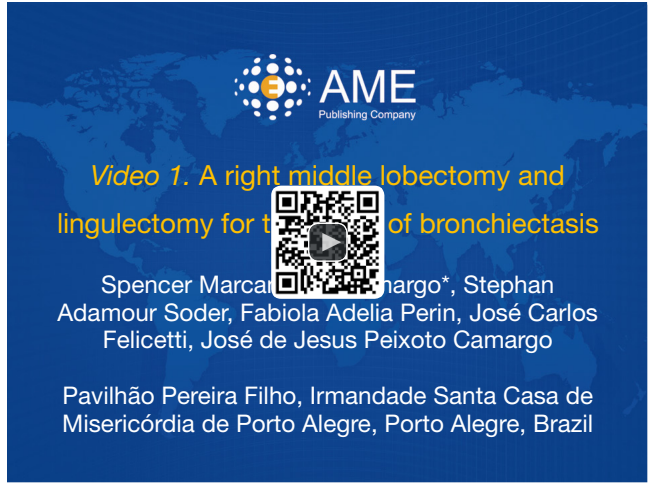

Figure 1 A right middle lobectomy and lingulectomy for treatment of bronchiectasis (12).

Available online: http://www.asvide.com/article/view/28276

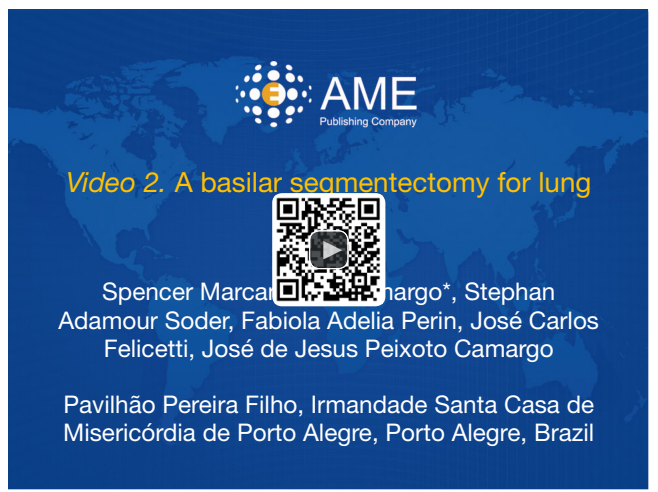

Figure 2 A basilar segmentectomy for lung cancer (13). Available online: http://www.asvide.com/article/view/28277

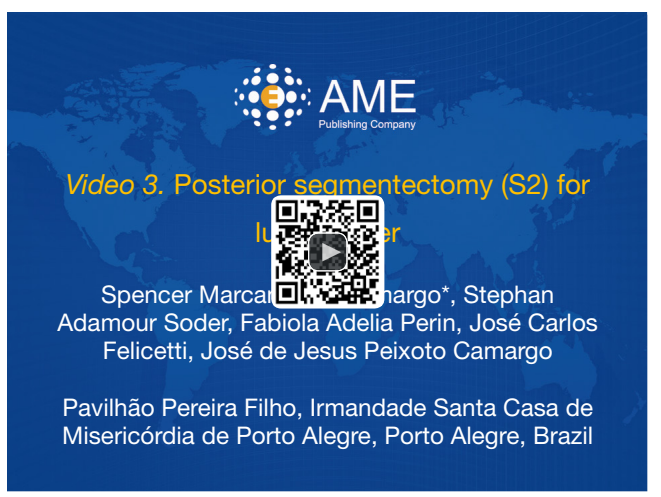

Figure 3 Posterior segmentectomy (S2) for lung cancer (14). Available online: http://www.asvide.com/article/view/28278 the stapler devices can easily pass around the vascular and bronchial branches. In cases of malignant disease, we routinely sample interlobar and at least two mediastinal nodal stations, even in wedge resections. When intending to do the segmentectomy, the interlobar lymph nodes must be sent to frozen section analysis. If any lymph node is positive for neoplasia, the segmentectomy is no longer indicated.

After the ligation of vascular structures, the segmental bronchus is clamped and the lung is ventilated in order to verify the intersegmental plane. When there is prominent collateral ventilation across the segments, is more difficult to precisely identify this plane. We cross-sectioned the parenchyma with stapler devices in most cases. When the segmentectomy is performed in young patients to treat bronchiectasis, sometimes we proceed to "stripping technique", in which cautery cutting or energy devices are used to divide the parenchyma while the anesthesiologist inflate the lung. This technique preserves the parenchyma architecture in the cross-sectioned line and improve the pleural cavity occupation by the remaining lung, but can promote more air leak if not well executed.

The videos in this article show: a right middle lobectomy and lingulectomy for treatment of bronchiectasis (Figure 1); a basilar segmentectomy for lung cancer (Figure 2); and posterior segmentectomy for lung cancer (Figure 3).

\section{Discussion}

The decision of perform an anatomic sublobar resection depends upon the clinical conditions and patient performance and the clinical staging. Pulmonary function tests as spirometry and diffusing capacity for carbon monoxide (DLCO) are assessed. For malignant diseases, clinical staging is conducted preferentially with a positron emission tomography-computed tomography (PET-CT) and a magnetic resonance imaging (MRI) from brain. If a mediastinal lymph node is clinically suspicious for neoplastic disease, it may be necessarily sampled before the resection procedure.

Worldwide, tumor size of $2 \mathrm{~cm}$ is considered the cutoff point in order to consider a sublobar resection. Several studies have shown that tumor size greater than $2 \mathrm{~cm}$ is an independent risk factor for recurrence in patients undergoing sublobar resections and the survival advantage 
or equivalence of sublobar resection is only demonstrated with tumors smaller than $2 \mathrm{~cm}(15)$. For these reasons, we do not indicate a segmentectomy as an intentional procedure in tumors $>2 \mathrm{~cm}$.

Several studies have shown that the distance between the tumor and surgical resection margin is an important determinant of local recurrence following sublobar resection. There is evidence of lower recurrence rates when the distance of tumor to margin is at least $1 \mathrm{~cm}(7.5 \%$ vs. $14.6 \%)(16)$ or when the ratio margin:tumor size is 1 or more $(6 \%$ vs. $25 \%)(17)$. We recommend that these conditions should be satisfied in order to do a sublobar resection. If the lesion is very close to the hilum or to the intersegmental plane and if there is concern to assure a safe distance of the nodule to the surgical margins as estimated by the chest image or after specimen removal, we prefer to perform a lobectomy.

Some retrospective studies have demonstrated better disease-free and overall survival of patients undergoing segmentectomy compared to wedge resection, reinforcing the margin concerns in wedge resections and the theoretical oncological benefits of segmentectomy in the context of sublobar resections $(18,19)$. A recent meta-analysis included nine studies with 7,272 patients and showed an overall survival of segmentectomy over wedge resection in tumor size $\leq 2 \mathrm{~cm}$ (20). However, the survival was equivalent in tumor size $\leq 1 \mathrm{~cm}$.

The lack of nodal sampling during wedge resections may have a strong impact in a potential difference of survival in this population compared to segmentectomies. In a retrospective review which included 3,916 patients of Surveillance, Epidemiology and End Results database with small $(<2 \mathrm{~cm})$ stage I NSCLC who underwent sublobar resection (21), from 2004 to 2013, the multivariate analysis didn't demonstrate a difference in overall survival between segmentectomy and wedge resection, but showed a great importance of lymph nodes examined, with progressive better survival with more lymph nodes removed. In this review, no lymph nodes were removed in $49 \%$ of the patients underwent to wedge resections. These data reinforce the importance and need of nodal sampling in every lung resection for neoplastic disease.

In the context of mixed-density or ground glass opacities dominant nodules, the survival outcomes between the sublobar resections seems to be equivalent (22).

There are several reasons why VATS segmentectomies are not executed very frequently in Brazil. The learning curve of a thoracic surgeon with lung resections by minimally invasive technique usually starts with nonanatomic resections, followed by lobectomies. The segmentectomy represents a more technically demanding procedure. In order to perform it, the surgeon must be fully capable of doing lobectomies, once the bronchial and vascular branches must be isolated more distally and beyond the fissures. Secondly, when treating small and peripheral nodules, the ease of wedge resection execution favors this one in opposite to an anatomical sublobar resection. Thirdly, in many cases, the surgeon not so used to VATS procedures prefer to convert to open surgery when segmentectomy is attempted, particularly in inflammatory diseases.

Unfortunately, despite of the existence of a national database of lung resections and other thoracic procedures, VATS lung resections is still much underreported in our country. The BSTS has working to stimulate surgeons and hospitals to register the surgeries performed in order to improve the quality of care and needs of our patients.

\section{Conclusions}

There is growing experience with lung resections by minimally invasive techniques around the country and the outcomes are promising. The national database created in 2014 should continuously show the profile of VATS procedures and stimulate the incorporation of these techniques by other centers. The oncological principles must always be preserved and followed by the thoracic surgeon. While we look forward to check the results of ongoing clinical trials regarding the sublobar versus lobar resections in nodules $<2 \mathrm{~cm}$, we believe that the segmentectomy is a feasible and an adequate oncological procedure and can be performed if the surgeon is capable of doing VATS lobectomies.

\section{Acknowledgments}

Funding: None.

\section{Footnote}

Provenance and Peer Review: This article was commissioned by the Guest Editors (Ricardo M. Terra and Paula A. Ugalde) for the series "Minimally Invasive Surgery Robotics and VATS in Brazil" published in fournal of Visualized Surgery. The article has undergone external peer review. 
Conflicts of Interest: All authors have completed the ICMJE uniform disclosure form (available at http://dx.doi. org/10.21037/jovs.2018.11.01). The series "Minimally Invasive Surgery - Robotics and VATS in Brazil" was commissioned by the editorial office without any funding or sponsorship. The authors have no other conflicts of interest to declare.

Ethical Statement: The authors are accountable for all aspects of the work in ensuring that questions related to the accuracy or integrity of any part of the work are appropriately investigated and resolved.

Open Access Statement: This is an Open Access article distributed in accordance with the Creative Commons Attribution-NonCommercial-NoDerivs 4.0 International License (CC BY-NC-ND 4.0), which permits the noncommercial replication and distribution of the article with the strict proviso that no changes or edits are made and the original work is properly cited (including links to both the formal publication through the relevant DOI and the license). See: https://creativecommons.org/licenses/by-nc-nd/4.0/.

\section{References}

1. Ginsberg RJ, Rubinstein L V. Randomized trial of lobectomy versus limited resection for T1 N0 non-small cell lung cancer. Ann Thorac Surg 1995;60:615-22.

2. Sesti J, Donington JS. Sublobar Resection: Ongoing Controversy for Treatment for Stage I Non-Small Cell Lung Cancer. Thorac Surg Clin 2016;26:251-9.

3. Okada M. Radical sublobar resection for small-diameter lung cancers. Thorac Surg Clin 2013;23:301-11.

4. Mendogni P, Tosi D, Rosso L, et al. VATS segmentectomy: an underused option? J Vis Surg 2017;3:136.

5. Altorki NK, Yip R, Hanaoka T, et al. Sublobar resection is equivalent to lobectomy for clinical stage $1 \mathrm{~A}$ lung cancer in solid nodules. J Thorac Cardiovasc Surg 2014;147:754-62.

6. Razi SS, Daskalaki D, Burack J. Current trends in lung resection for T1a non-small cell lung cancer: is lobectomy still the answer? J Thorac Dis 2017;9:E164-5.

7. Kates M, Swanson S, Wisnivesky JP. Survival following lobectomy and limited resection for the treatment of stage I non-small cell lung cancer $\leq 1 \mathrm{~cm}$ in size: A review of SEER data. Chest 2011;139:491-6.

8. Terra RM, Kazantzis T, Pinto-Filho DR, et al. Anatomic pulmonary resection by video-assisted thoracoscopy: the Brazilian experience (VATS Brazil study). J Bras Pneumol
2016;42:215-21.

9. Soder SA, Barth F, Perin FA, et al. Anatomic pulmonary resection via video-assisted thoracic surgery: analysis of 117 cases at a referral center in Brazil. J Bras Pneumol 2017;43:129-33.

10. Zhou ZL, Zhao H, Li Y, et al. Completely thoracoscopic lobectomy for the surgical management. Chin Med J (Engl) 2013;126:875-8.

11. Zhang P, Zhang F, Jiang S, Jiang G. Video-Assisted Thoracic Surgery for Bronchiectasis. Ann Thorac Surg 2011;91:239-43.

12. Camargo SM, Soder SA, Perin FA, et al. A right middle lobectomy and lingulectomy for treatment of bronchiectasis. Asvide 2018;5:856. Available online: http://www.asvide.com/ article/view/28276

13. Camargo SM, Soder SA, Perin FA, et al. A basilar segmentectomy for lung cancer. Asvide 2018;5:857. Available online: http://www.asvide.com/article/ view/28277

14. Camargo SM, Soder SA, Perin FA, et al. A basilar segmentectomy for lung cancer. Asvide 2018;5:858. Available online: http://www.asvide.com/article/ view/28278

15. Tsubokawa N, Tsutani Y, Miyata Y, et al. Segmentectomy Versus Lobectomy for Radiologically Pure Solid Clinical T1a-bN0M0 Lung Cancer. World J Surg 2018;42:2493-501.

16. El-Sherif A, Fernando HC, Santos R, Pettiford B, Luketich JD, Close JM, et al. Margin and local recurrence after sublobar resection of non-small cell lung cancer. Ann Surg Oncol 2007;14:2400-5.

17. Schuchert MJ, Pettiford BL, Keeley S, et al. Anatomic segmentectomy in the treatment of stage I non-small cell lung cancer. Ann Thorac Surg 2007;84:926-32; discussion 932-3.

18. Miller DL, Rowland CM, Deschamps C, et al. Surgical treatment of non-small cell lung cancer $1 \mathrm{~cm}$ or less in diameter. Ann Thorac Surg 2002;73:1545-50; discussion 1550-1.

19. Sienel W, Dango S, Kirschbaum A, et al. Sublobar resections in stage IA non-small cell lung cancer: segmentectomies result in significantly better cancerrelated survival than wedge resections. Eur J Cardiothorac Surg 2008;33:728-34.

20. Xue W, Duan G, Zhang X, et al. Meta-analysis of segmentectomy versus wedge resection in stage IA nonsmall-cell lung cancer. Onco Targets Ther 2018;11:3369-75.

21. Yendamuri S, Dhillon SS, Groman A, et al. Effect of 
the number of lymph nodes examined on the survival of patients with stage I non-small cell lung cancer who undergo sublobar resection. J Thorac Cardiovasc Surg 2018;156:394-402.

doi: 10.21037/jovs.2018.11.01

Cite this article as: Camargo SM, Soder SA, Perin FA, Felicetti JC, Camargo JJ. Video-assisted thoracic surgery segmentectomies: Brazilian experience. J Vis Surg 2018;4:238.
22. Tsutani Y, Miyata Y, Nakayama H, et al. Appropriate sublobar resection choice for ground glass opacitydominant clinical stage IA lung adenocarcinoma: Wedge resection or segmentectomy. Chest 2014;145:66-71. 